\title{
Waste Management Firms as Catalysts for Developing SME's Circular Business Models: the Possibilities of Industrial Symbiosis
}

\author{
${ }^{1}$ Han van Kleef and ${ }^{2}$ Donald Ropes
}

1,2 Innovation \& Entrepreneurship at the Business Research Center (BRC) of Hogeschool Inholland, Haarlem UAS, Netherlands

\begin{abstract}
The purpose of this research was to explore possibilities for waste management firms (WMFs) to act as lead firms in industrial symbiosis (IS) processes with small and medium enterprise (SME) clients in order to promote circular business models. We were curious to see how willing, and able four local WMFs were regarding the adoption of a firm lead role and under what conditions. We used a case study design because of the lack of research on the topic and the explorative nature of the research itself. First, we interviewed nine representatives from four WMFs using a semi-structured interview protocol. We then presented our results to the representatives as a basis for further discussion. We found that WMFs are open to adopting the various roles associated with a lead firm position in industrial symbiosis but need various kinds of support in order to so, for example, in coordinating the IS - network and for financing the activities. Our research is original in the sense that we look at the concept of IS from the specific context of a WMF-SME symbiotic relationship. We also contribute to both the IS literature as well as that of new business model development. Management implications include understanding why firms are willing to explore new business models with their client partners.
\end{abstract}

Keywords: Circular business models, Waste management firms, SMEs, Industrial symbiosis

\section{Introduction}

\subsection{Problem Statement}

The European Union (EU) and its member states are dedicated to developing a more sustainable future through promoting a circular economy (Commission, 2015). A circular economy is an economic and industrial system that decouples economic activity from the consumption of resources that are finite, designs waste out of the system and keeps products in use. The EU considers WMFs to have a central role in promoting and facilitating a circular economy. This is because they decide how the waste hierarchy, which aims for minimal environmental damage, is practised. The waste hierarchy is a model that prioritizes waste prevention, preparation for re-use, recycling, the recovery of energy, and the removal of waste by means such as landfilling. Circular business models aim towards the top of the hierarchy where there is no more waste.

At the same time, The EU sees SMEs as having a crucial role in promoting a circular economy. The SME sector is large and because of these possibilities for developing a circular economy here are great. Yet research shows that the prevention of waste and the design of circular economic business processes that follow the waste hierarchy are not common in SME's, nor in most firms (Jonker et al., 2016). It seems that business management is still dominated by subjects as economic feasibility, marketing, finance and technical issues. In addition, most firms typically consider sustainability mainly in terms of recycling, and the reduction of energy and resource use, driven by a focus on efficiency (Jonker et al., 2016). This is especially the case for SMEs, where sustainability policy is typically absent, environmental measures are limited to 
the individual firm and its established partners, and the existing business model remains dominant (Jonker et al., 2016). Consequently, ecological and social issues are overlooked.

Many SMEs express their will to contribute to sustainability (Jonker et al., 2016) but see many barriers to do this (Rizos et al., 2015; Arfi, Hikkerova and Sahut, 2018; Damert and Baumgartner, 2018; Ghenţa and Matei, 2018; Josserand, Kaine and Nikolova, 2018; van Orden et al., 2018; Wiesner, Chadee and Best, 2018). These barriers include, but are not limited to, such things as a lack of information on new technologies and possibilities, an absence of technical and managerial capabilities and knowledge, and a dearth of a network that supports innovation towards a circular economic product, services and business processes (Rizos et al., 2015).

One type of network that could help SMEs to develop circular business models is an IS network. This is a specific type of network that engages different organizations seeking to foster ecoinnovation through creating and sharing knowledge that yields jointly profitable transactions for novel resourcing of inputs, value-added applications for non-product outputs such as waste streams, new business models and improved technical processes (Lombardi and Laybourn, 2012, p. 31).

Thus, participation in networks aimed at IS has the possibility to stimulate innovation that is oriented towards sustainable development, e.g. circular economy. Through participation in IS networks, SMEs can gain competencies they might not be able to get elsewhere. In his doctoral dissertation on WMFs and IS in Sweden, Aid (2017) found that WMF's have the ability to stimulate IS and that the waste sector has room for the development of new business models and roles for WMFs that would facilitate IS. For example, WMFs could act as a regional IS facilitator, which entails such activities as bringing firms together, organizing meetings with external experts and facilitating communication with governmental policymakers. Another possibility Aid (2017) mentions is that WMFs act as 'Eco-Industrial Park Managers' by using their waste treatment expertise, knowledge of legal permits and waste market knowledge to manage industrial parks in the direction of industrial symbiosis or even to develop eco-industrial parks. WMFs could also use their knowledge and capabilities for promoting activities such as dual flow material (procurement plus waste management) and energy management, material matching and value-chain development and even advise firms about high-value resource extraction, which refers to the idea that waste is mined for precious resources that can be used elsewhere. Our research focused on understanding through a case study why and how WMFs could advance a circular economy through developing IS with their SME clients.

\subsection{The Case}

The case started in June of 2018 in Haarlem, The Netherlands, when a meeting was held at an industrial park called The Waarderpolder. The meeting was about how to efficiently and effectively extract and utilize possible value from company waste streams. Present at the meeting were local business owners or directors, representatives from six different WMF's, local and regional government representatives and university researchers.

During the discussions that took place during the meeting, it became clear that each of the WMF's present was aware of their key position in a transition to circular business models. The representatives discussed the fact that their firms have extensive knowledge about waste streams, have both SME and large-firm partners, and have - perhaps most importantly - the ambition to develop new business models aimed at promoting a circular economy.

Based on this meeting, a project team was formed that would further explore the possibilities of a WMF-SME relationship. Members of the project team were from local and regional 
government (who financed the research), a non-governmental agency that coordinated the project, a representative from a national industrial park board and university researchers.

In September of 2018, four WMF's were approached to see if they were willing to participate in the research project, which would entail interviews with strategic personnel and a workshop where the results of the research would be presented and discussed. All four agreed to take part.

\section{Literature Review}

In the literature, there is some evidence that circular economic production processes on a company level can be the outcome of networks aimed at IS (Velenturf and Jensen, 2015). Lombardi and Laybourn (2012) propose that IS can be instrumental for innovation with an orientation towards sustainable development, suggesting that an IS network enables mutual learning, information sharing among the participants, and the creation of knowledge for new business opportunities. Eco-innovations (as the outcome of an innovation process that is orientated towards sustainable development) are stimulated by, for example, changing government rules and legislation or by being facilitated by the network in which a company participates. Through participation in the network, the culture of organizations can change; the firm can become more efficient in their business processes and more alert to new business opportunities, and ways to use resources more sustainably may be developed.

It is important to note that while the exchange of physical resources through an IS network is a vital aspect, participation in the network itself is also valuable, providing opportunities and motivations for collective activities such as solving complex problems and organizing innovation (Mirata and Emtairah, 2005).

\subsection{IS-Network Evolution and the Role of the Lead Firm}

In this research, we position the WMF as a lead firm in the IS process. We understand IS to be a process and should be approached as such, rather than a state (Paquin and Howard-Grenville, 2012). For this reason, we need to understand how IS is started and how it evolves. Empirical research from an IS as process perspective shows that IS starts in three ways (Boons, Spekkink and Mouzakitis, 2011; Paquin and Howard-Grenville, 2012). The first is through emergence or self-organization. According to Ghali, Frayret, \& Ahabchane (2017), self-organized IS 'is characterized by self-motivated industrial actors who intentionally or not identify product exchanges or resource-sharing opportunities.' However, research shows that an IS network does not often develop spontaneously and does not facilitate itself (Behera et al., 2012). Chertow \& Ehrenfeld (2012) found that IS networks need to be facilitated and coordinated, even among companies that already cooperate in other ways. It is therefore important to also understand how successful IS-networks operate and how they can be designed and developed. A second way an IS process starts is through facilitation by a third party. Hewes and Lyons (Hewes and Lyons 2008) observed that individuals such as urban planners play a crucial role in developing IS within industrial parks. They use the term 'champion' to describe an individual who can effectively apply social aspects of organizing such as trust and embeddedness in order to promote collaboration on environmental management efforts. Third-party organizations typically aim to develop IS through varying ways of facilitation such as bringing together potential IS actors and facilitating their collective learning about the possibilities of IS (Hewes \& Lyons, 2008), through developing a brokerage structure where firms can develop IS through a market system (Lee, Park, Yoon, \& Park, 2010) or by organizing a pilot with interested firms (Boons et al., 2011). IS can also be facilitated in its evolution through top-down driven processes. In these cases, governments plan and develop IS by creating local physical and institutional conditions. Physical conditions are those related to physical infrastructure, for example, land and roadway construction. Institutional conditions consider such things as preferential governmental policies for the forming of IS, activities aimed at recruiting firms and 
management support for coordinating the IS processes (Sun, Spekkink, Cuppen, \& Korevaar, 2017). Research by Costa, Massard, \& Agarwal (2010) highlights the crucial influence that government policies have on the formation of IS networks.

In our literature search, we found that the idea of a lead firm is discussed solely in cases where IS is an emergent phenomenon. It seems that IS emerges due to the initiatives of what is called an 'anchor tenant', which stems from the original idea of a large retail department store that creates demand for smaller retailers in the larger store's proximity. In the IS literature, we read, anchor tenants are represented as large manufacturing firms or power plants that produce sizeable amounts of waste energy that other smaller firms can use (Sun et al., 2017). Korhonen \& Snakin (2001) suggest that an anchor tenant is an organization that has the influence to drive material and energy flows, that is already engaged in environmental management, and that might serve as the key actor in a network of actors that gradually emerges, driven by collaborative inter-organizational environmental management. In this research, we position the WMF as an anchor tenant, or as we refer to it, a lead firm.

\subsection{Proximity and Learning in IS-Networks}

Chertow (2000) found that although geographical proximity offers possibilities for cooperation and synergy, other forms of proximity may also advance learning and innovation between companies in a network. For example, Boschma (2005) discusses the idea of cognitive proximity, in which people share a common base of knowledge and expertise that enables them to learn faster with each other. He also proposes the idea of organizational proximity, defined as the extent to which relations are being shared within and between organizations. Although a low degree of this kind of proximity can hinder the exchange of complex knowledge, in combination with a stable cooperation structure, new solutions can be developed. Social proximity also plays a role in cooperation and knowledge exchange. Granovetter (1973) showed that economic relations, on the level of individuals, are embedded in a social context where trust, friendship and relatedness are vital aspects for learning and innovation between firms. Theory on social embeddedness, which refers to the extent to which economic activity is limited by noneconomic institutions, suggests that the more the relations of a company are embedded in a social network, the bigger its innovation capability is because trust and involvement stimulate interactive learning (Uzzi, 1997). The presence or development of social capital is important to motivate participants to contribute in ways that exceed self-interest (see also Gulati,1998). Lastly, geographical proximity in combination with cognitive proximity can be sufficient to promote interactive learning. Geographical proximity is closely linked to Chertow's (2000) concept of IS. Boschma (2005) proposes that if cognitive proximity is present, advanced ICT can simulate geographical proximity, inferring that geographical proximity is thus neither a sufficient condition nor necessary to promote learning among companies.

Learning in IS relates to the ability a firm has in gathering, assimilating and using external knowledge, which is referred to in the literature as absorptive capacity (ACAP). The most widely cited definition of ACAP comes from Cohen \& Levinthal (1990), who view it as a firm's ability to value, assimilate and exploit knowledge from external sources. Antecedents to ACAP are prior knowledge stocks, flows of knowledge and communication.

\subsection{Lead Firm Capacities for Initiating IS}

Emergent forms of IS begin with bottom-up processes that rely heavily on an organization's capacity to mobilize partners, to influence the local social and physical environment and its absorptive capacity (Ghali, Frayret and Ahabchane, 2017). A firm's capacity to mobilize partners may lie in power; it has to influence the supply chain of which it is a part, as well as its level of social embeddedness. According to Gereffi \& Lee (2012), a lead firm exercises varying degrees of power through the coordination of suppliers without having any direct ownership of the firms. Capability to influence the local social environment is related to the embeddedness of the lead 
firm in the region, mutual trust and the firm's absorptive capacity. Being socially embedded in a group signifies that an actor's behaviour is influenced by other actors or by the social norms of that group (Granovetter, 1973). Personal relationships and other types of social ties can provide noneconomic incentives for forming IS relationships and, if cultivated properly, result in mutual trust, which also seems to be a key element in the evolution of IS (Hewes and Lyons, 2008).

\subsection{Research Question}

Thus, the transition towards a circular economy plays a major role in European Union and member state policy. The realization of sustainability-related goals depends on the participation of companies, but these experience difficulties in directing their innovations towards a circular economy. WMFs might, due to relationships with SME's combined with their knowledge and expertise on waste and resource flows, be able to fulfil the role of facilitator and promote IS networks aimed at a circular economy. However, both WMFs and SMEs will probably need considerable internal development regarding their vision, their mission, strategy, etc.) before a new role can be fulfilled. Following that, it may be necessary for firms to decide which of their present capacities fit the new role, which ones need to be developed, and to what extent new business may cannibalize existing revenue streams. Although IS-networks may lead to ecoinnovation, firms will need to improve their collaboration tactics and strive for long-term partnerships, complemented with policy leadership and tactical lobbying. However, how this is done is still unknown. Aid (2017), for example, specifically discusses the need for research on innovative partnerships and new business model exploration in the context of a WMF-SME relationship. Our research helps to fill this gap and contributes to our understanding of how WMFs can use their position as a lead firm in IS- networks of their SME clients.

Based on this, we propose the following research question:

What role can waste management firms fulfil in advancing industrial symbiosis for a circular economy, especially in relation to SME's?

We explore this question via a study of the case presented above in section 1.2 . In this case study, four WMFs operating in The Netherlands took part in interviews and interactive sessions with researchers, local and regional government and NGO representatives, and each other.

\section{Research Methodology}

We were trying to gain a holistic view of the context of the case - its social structures, implicit and explicit rules and ways of working in the natural setting where WMFs operate and for this reason, propose that qualitative data is the most appropriate for our research (Miles and Hubermann, 1994; Yin, 2003). We gathered data using two methods.

First, we interviewed nine different upper-level managers from the four WMFs. We developed a semi-structured interview protocol that would guide the interviews (see appendix). We chose this technique because we needed to assure comparability of data between the researchers. This raises validity (Seidman, 2013). We were also dealing with a complex case where a mixedmethods approach to data collection was used, which also requires more stringent prior instrumentation (Miles, Huberman and Saldana, 2014). In order to guide the interview protocol, we developed several sub-questions:

1.What are the policies of the participating WMFs, regarding a circular economy?

2. What experiences, if any, do WMFs have with client firms regarding the circular economy?

3. What opportunities for more intense cooperation with SMEs on the subject of circular economy do WMFs see? 
4.Which client firms of the WMFs would be the most open to participate in closer cooperation? 5. What are the current barriers and enablers to cooperation between WMFs and their SME client firms?

Interviews varied in length between 30 and 50 minutes. Each was recorded, transcribed, and entered into MaxQDA, which is software designed for analyzing qualitative data. Consequently, two researchers coded the data separately and then compared the results. This led to only minor recoding. Next, answers to each of the interview questions were synthesized into narratives (Popay et al., 2006). These narratives were then used to formulate answers to the subquestions, which were discussed separately with each of the interviewees as a sort of member check (Creswell and Miller, 2010). This process resulted in only very minor amendments to the results.

The second type of data we collected came out of a workshop with the interviewees, other representatives from the WMFs and members of the project team. Notes of this workshop were taken by two researchers and then compared for agreement. Data in the form of text written on flip-overs were also analyzed. These data were then discussed with the project team members and subsequently combined with the interview data in order to answer our main research question.

\section{Data Analysis and Interpretation}

We first present the findings of the interview data, structuring it along the lines of our five subquestions. Following this, we present the findings from the workshop.

\subsection{Findings of the Interview Data}

SQ1. What are the policies of the WMFs, regarding a circular economy?

Each of the four WMFs regards the circular economy as a pressing theme, and all have developed a related vision as well as specific policies. Some of these policies have been translated into strategies, operational plans and/or specific working methods. Each firm was able to cite examples of projects they were running aimed at promoting a circular economy. We also found that many of their larger clients and several SME clients are working on circular economy as well. All four WMFs are interested in developing new services that can assist companies in developing new circular business models.

SQ2. What experiences, if any, do WMFs have with client firms regarding the circular economy?

Current projects in which close cooperation plays a role are mainly with bigger companies and not SMEs. These projects focus on improving waste separation aimed at generating clean monostreams, a first step in the circular economy process. Sometimes projects focus on preventing the occurrence of low-value waste that cannot be recycled, which usually happens in cooperation with a supplier of the customer company. However, the majority of projects are directed at lower levels of the waste hierarchy and aim at improving recycling, recovering or repurposing, not maintaining added value. According to the interviewees, the main reason client firms do not put more effort into a circular economy is of a financial nature. Only in times of economic growth are firms willing to accept extra costs; when business is poor, their efforts towards a circular economy decrease. Client firms are, according to the WMFs, of the opinion that they have to invest too many financial resources and other efforts to harvest the advantages of a circular economy. WMFs are convinced that tailor-made and economically attractive solutions for their client firms need to be developed if a circular economy is to be promoted. The presence of trust, based on a long-lasting relation, would be most helpful if not crucial. 
SRQ3. What opportunities for more intense cooperation with SMEs on the subject of circular economy do WMFs see?

Waste management firms see many opportunities for closer cooperation with their clients. Interviewees discussed things such as decentralized waste processing, digital techniques for improving on-site waste management and return logistics as all viable possibilities. They also talked about their role in starting a dialogue with the client firm's suppliers to improve both the stock of information and increase consciousness about the effects of their products on waste management. Advice to client SMEs could be given in regular meetings about running services or in negotiations around new contracts. The WMFs see cost consciousness and hindrance of waste that companies experience as providing a powerful starting point for any advice trajectory. In addition, WMFs all mentioned that stricter laws and regulations concerning waste also form stimuli for companies to re-evaluate their waste streams.

SRQ4. Which client firms of the WMFs would be the most open to participate in closer cooperation?

In most companies, there are improvement opportunities in the field of waste, and there is potential for closer cooperation with waste management firms to further a circular economy. However, in smaller SME's the possibilities are limited because waste streams are small. Consequently, clients' suppliers are not inclined to facilitate any efforts in new circular business models. Especially SME's with fewer than 50 employees are, according to the interviewees, too small to absorb any higher cost of waste management for a circular economy, which in turn could lead to a loss of competitive advantage. However, small client firms wanting to promote a circular economy could do so through improving logistic processes, for example, through reverse logistics or in cooperation between other geographically proximal SMEs and the WMF.

SQ5. What are the current barriers and enablers to cooperation between WMFs and their SME client firms?

Respondents were unanimous in their reply, naming the dominant way of thinking in business models and profits as the main barrier. Measures to realize a circular economy should not increase costs but should actually provide revenues. However, the social and ecological values that are a focus of sustainable development play on a societal level and cannot be translated easily into monetary values. Therefore, in conventional business practices, they remain out of the management picture.

In that light, laws and regulations still do not push companies, supply chains and their customers enough into the direction of circular economic production and consumption practices. Governments could do much more via their purchasing department and through subsidies for innovation and the development of new products and services. They could inform consumers and companies more strongly to help increase awareness about the issues. On a local level, governments could start initiatives to promote cooperation between companies on the subject of the circular economy. A barrier is that companies do not like to give insight into their business processes. In SME's, the focus on cost reduction is a limiting factor to eco-innovation. On the other hand, the hindrance that companies experience from waste in their business processes may provide room for advice on new solutions.

\subsection{Findings from the Participant Workshop}

During the four-hour workshop, several important points were raised in regards to the conditions under which the WMFs would be willing to experiment with a facilitating role to advance IS in the context of circular economy and SME's. 
The first condition is that SME's would need to be from a specific region or a specific sector that is experiencing pressures from governmental regulations to develop circular business models. Digitalization of business processes was mentioned, which is a way firms can reproduce geographical proximity.

Pressures from other firms or consumers to become more circular were also discussed as a crucial aspect. Another condition WMF representatives mentioned is that the SME's who participate in the network help pay for the costs associated with the development of the IS network, including any activities by the WMFs, for example, in their role as IS regional facilitators. Funding from the government would also be acceptable. WMFs see their possible role as advisers and would expect to take this role on. However, they clearly indicated that local or provincial governments should participate in pilot projects with SME's in which experiments are started with new forms of service by WMFs. These pilots would need to be funded as well, supported by experts in developing new business models and coordinated by experts in the field of open-innovation management. Also important is the idea that government could also take the initiative to bring companies together and coordinate a platform as well as pressure firms through local regulations to become more circular.

During the workshop, WMFs also discussed how they would fill their roles at an operational level. The first thing they would do they called "start with low hanging fruit". WMFs have the view that projects that immediately focus on the higher levels of the waste hierarchy (i.e. prevention of waste, redesign of products and production processes) cannot be sold to their client firms because the steps needed are too great. Instead, they suggest focusing on harvesting the 'low hanging fruit', where no or very little additional costs are involved and where hindrance of waste in business processes is reduced.

Another point was about building trust and solid networks. WMFs talked about the importance of first building trust with clients who participate in a pilot, gain new knowledge (to develop a new service concept and business model of the waste management firms), expand the network, and only then move to more ambitious goals higher in the waste hierarchy. Many SMEs have sustainability ambitions, but the topic of waste is not high on their agenda and should be "seduced" to invest in extra efforts.

Finally, there should be a focus on scalability. Pilot projects should be focused on developing scalable solutions or approaches applicable in multiple chains or sectors. To that end, the participation in pilots of organizations that represent specific business sectors, supply chains, regions or business parks would be useful.

\section{Conclusion and Recommendations}

Here we answer our main research question, which was 'What role can waste management firms fulfil in advancing industrial symbiosis for a circular economy, especially in relation to SME's?' We first presented a discussion on IS networks as a way to frame the case study and used IS theory as a lens to understand the roles that WMFs could have in developing a circular economy. We found that IS processes do not start spontaneously but have to be organized, coordinated and facilitated. This can be done by a lead firm that is in a position to influence other actors in a region or supply chain, or by governments, through laws and regulations or through facilitating measures like platforms or networks. In both the interviews and the workshop data, we see that WMFs discussed these aspects of developing an IS network, stating certain conditions for their taking on a firm lead role. They spoke about how governments and third-party experts would be needed in order for them to become a lead firm. Financial and regulatory incentives would be helpful, as well as coordination of waste and resource logistics between companies in a region or chain and the organization of a platform to promote cooperation and the monitoring and 
evaluation of efforts. If this was the case, the role they see for themselves is closely related to that of a regional IS facilitator, as discussed above (Aid, 2017).

We also found two other aspects of IS theory that came out in the findings, namely proximity and learning. In order to create industrial symbiosis processes, some kind of proximity between companies needs to be present, as well as mutual trust and social embeddedness. In both the interviews and the workshop, WMFs discussed the importance of regional development as a precursor to IS. They also spoke about how building trust would be a critical success factor for a successful role as lead firm, which also underpins the theory. Trust, and greater interest in IS could be stimulated by helping companies to first 'pick the low hanging fruits of waste management that are oriented towards sustainable development. Only after this initial trial phase could efforts be made to help them to move to more cooperative ways of waste prevention with customers, suppliers or other companies.

The specific capacities given in the literature were not actually discussed by the WMFs, except that they would need to develop new knowledge and internal processes in order to assume a lead firm role. Aspects of absorptive capacity were not explicitly stated, but individuals in the workshop might not have been able to relate their positions in an IS regarding this as they tried to envision themselves as lead firms.

In this study, we found that four Dutch WMFs acknowledged their position as a favourable position to becoming lead firms in IS-networks among their SME clients for the purpose of advancing a circular economy. They have suitable policies and strategies; they can offer new techniques to improve waste management, separation and processing, and they can provide information to increase awareness on sustainability. However, they are aware of the external conditions and internal competencies they would need to acquire in order to fulfil their role as a lead firm.

The results of our study help to contribute to the literature (e.g. Centobelli et al, 2020; Fraccascia et al, 2019; Lüdeke-Freund and Bocken, 2019) on how new business models can be developed in WMF-SME IS-networks. Our study shows the importance of a systemic perspective to design circular business models, also serving to illustrate the aspect of context-sensitivity of business model development for IS. The research also gives guidance for practical steps that could facilitate a firm's transition to an IS business model.

We are aware of the limitations of our research. A one-shot case study is not a powerful research design (Cook, 1983). Another threat to our findings concerns the interventionist nature of the research; both researchers were part of the project team who developed the workshop, and the notes we recorded might be biased to reflect the pre-supposed outcomes of the project group as a whole.

We propose that more research needs to be done in order to test our outcomes across a broader field as well as across different sectors. We would also argue that conducting (quasi) experiments to come up with tested design principles would be very useful for developing further knowledge about how lead firms evolve in their roles. Although the current results could also be used by practitioners when trying to understand how IS -networks are formed and crucial aspects surrounding their development, more research is needed to understand the crucial role of context, especially in regards to the sector in which the SME clients are operating.

\section{References}

- Aid, G., (2017). Operationalizing Industrial Ecology in the Waste Sector: Roles and tactics for circular value innovation. Linköping University Electronic Press. 
- Arfi, W., Ben, Hikkerova, L., and Sahut, J.-M. (2018). External knowledge sources, green innovation and performance. Technological Forecasting and Social Change. Elsevier. CrossRef

- Behera, S., K., et al. (2012). Evolution of designed industrial symbiosis networks in the Ulsan Eco-Industrial Park: research and development into business as the enabling framework. Journal of Cleaner Production. Elsevier. CrossRef

- Boons, F., Spekkink, W., and Mouzakitis, Y., (2011). The dynamics of industrial symbiosis: a proposal for a conceptual framework based upon a comprehensive literature review. Journal of Cleaner Production. Elsevier. CrossRef

- Boschma, R., (2005). Proximity and innovation: a critical assessment. Regional studies. Taylor \& Francis. CrossRef

- Camisón, C., and Forés, B., (2010). Knowledge absorptive capacity: New insights for its conceptualization and measurement. Journal of Business Research. Elsevier Inc. CrossRef

- Centobelli, P., Cerchione, R., Chiaroni, D., Del Vecchio, P., and Urbinati, A., (2020). Designing business models in circular economy: A systematic literature review and research agenda. CrossRef

- Chertow, M., and Ehrenfeld, J., (2012). Organizing Self-Organizing Systems. Journal of Industrial Ecology. Wiley Online Library. CrossRef

- Chertow, M., R., (2000). Industrial symbiosis: literature and taxonomy. Annual review of energy and the environment. CrossRef

- Cohen, W., M., and Levinthal, D., A., (1990). Absorptive Capacity: A New Perspective on Learning and Innovation. Administrative Science Quartely. CrossRef

- Commission, E., (2015). Closing the loop-an EU action plan for the circular economy. $\operatorname{COM}(2015) 614$ final.

- Cook, T., D., (1983). Quasi-Experimentation: Its Ontology, Epistimology, and Methodology. Morgon, G. (ed.) Beyond Method: Strategies for Social Research. London.

- Creswell, J., W., and Miller, D., L., (2010). Determining Validity in Qualitative Inquiry, Theory into Practice. Theory into Practice. CrossRef

- Damert, M., and Baumgartner, R., J., (2018). External Pressures or Internal Governance-What Determines the Extent of Corporate Responses to Climate Change? . Corporate social responsibility and environmental management. Wiley Online Library. CrossRef

- Fraccascia, L., Giannoccaro, I., and Albino V., (2019). Business models for industrial symbiosis: A taxonomy focused on the form of governance. Resources, Conservation and Recycling. CrossRef

- Gereffi, G., and Lee, J. (2012). Why the world suddenly cares about global supply chains. Journal of supply chain management. Wiley Online Library. CrossRef

- Ghali, M., R., Frayret, J.-M., and Ahabchane, C., (2017). Agent-based model of selforganized industrial symbiosis. Journal of Cleaner Production. Elsevier. CrossRef

- Ghenţa, M., and Matei, A., (2018). SMEs and the circular economy: From policy to difficulties encountered during implementation. Amfiteatru Economic. Bucharest Academy of Economic Studies, Faculty of Commerce. CrossRef

- Granovetter, M. S. (1973). The strength of weak ties. American Journal of Sociology. CrossRef

- Gulati, R., (1998). Alliances and Networks. Strategic Management Journal. CrossRef

- Hewes, A., K., and Lyons, D., I., (2008). The humanistic side of eco-industrial parks: champions and the role of trust. Regional studies. Routledge. CrossRef

- Jonker, J., et al. (2016). Één zwaluw voorspelt veel goeds; Resultaten van het landelijke onderzoek 2016-2017 naar Business Modellen voor de Circulaire Economie. Doetinchem: Stichting OCF 2.0 . 
- Josserand, E., Kaine, S. and Nikolova, N., (2018). Delivering sustainability in supply networks: Achieving networked multi-stakeholder collaborations. Business Strategy and the Environment. Wiley Blackwell. CrossRef

- Korhonen, J., and Snakin, J., P., (2001). An anchor tenant approach to network management: considering regional material and energy flow networks. International Journal of Environmental Technology and Management. Inderscience Publishers. CrossRef

- Lombardi, D., R., and Laybourn, P., (2012). Redefining Industrial Symbiosis: Crossing Academic-Practitioner Boundaries. Journal of Industrial Ecology. CrossRef

- Lüdeke-Freund, F., Gold, S., and Bocken, N., M., P., (2019). A review and typology of circular economy business model patterns. Journal of Industrial Ecology. CrossRef

- Miles, M., B., Huberman, A., M., and Saldana, J., (2014). Qualitative data analysis: a methods sourcebook. Thousand Oaks: Sage.

- Miles, M., B., and Hubermann, A., M., (1994). Qualitative Data Analysis. 2nd edn. Thousand Oaks: Sage.

- Mirata, M., and Emtairah, T., (2005). Industrial symbiosis networks and the contribution to environmental innovation: the case of the Landskrona industrial symbiosis programme. Journal of cleaner production. Elsevier. CrossRef

- Van Orden, C., et al. (2018). Onderzoek naar belemmeringen en ondersteuningsbehoefte: Sociale ondernemingen in Noord-Nederland: een verkenning. Sociaal Bestek. CrossRef

- Paquin, R., L., and Howard-Grenville, J., (2012). The evolution of facilitated industrial symbiosis. Journal of industrial Ecology. Wiley Online Library. CrossRef

- Rizos, V., et al. (2015) The Circular Economy: Barriers and Opportunities for SMEs. Brussels.

- Seidman, I., (2013). Interviewing as qualitative research: A guide for researchers in education and the social sciences. 3rd edn. London, New York: Teachers College Press.

- Sun, L., et al. (2017). Coordination of industrial symbiosis through anchoring. Sustainability. Multidisciplinary Digital Publishing Institute. CrossRef

- Uzzi, B., (1997). Social Structure and Competition in Interfirm Networks: The Paradox of Embeddedness. Administrative Science Quarterly. Johnson Graduate School of Management, Cornell University. CrossRef

- Velenturf, A., P., M., and Jensen, P., D., (2015). Promoting industrial symbiosis: Using the concept of proximity to explore social network development. Journal of Industrial Ecology. Wiley Online Library. CrossRef

- Wiesner, R., Chadee, D., and Best, P., (2018). Managing change toward environmental sustainability: A conceptual model in small and medium enterprises. Organization \& Environment. Sage Publications Sage CA: Los Angeles, CA. CrossRef

- Yin, R., K., (2003). Case Study Research: Design and Methods, Applied Social Science Research Methods Series. Thousand Oaks: Sage.

\section{Appendix}

Sub questions and the related interview questions.

\begin{tabular}{|l|l|}
\hline Sub Question & \multicolumn{1}{c|}{ Interview question } \\
\hline $\begin{array}{l}\text { 1. What policies and visions do the } \\
\text { participating waste collectors have, } \\
\text { regarding CE? }\end{array}$ & $\begin{array}{l}\text { How urgent is the issue of circular economy } \\
\text { (CE) for your business? }\end{array}$ \\
\hline & $\begin{array}{l}\text { Does your company have a CE policy and a } \\
\text { vision on it? }\end{array}$ \\
\hline & $\begin{array}{l}\text { If so, where is this documented? Where can } \\
\text { one find it? }\end{array}$ \\
\hline
\end{tabular}


Han van Kleef and Donald Ropes

Waste Management Firms as Catalysts for Developing SME's Circular Business Models: the Possibilities of Industrial Symbiosis

\begin{tabular}{|l|l|}
\hline & $\begin{array}{l}\text { If so, has it been translated into a strategic } \\
\text { plan? }\end{array}$ \\
\hline $\begin{array}{l}\text { 2. What are the WMFs experiences in } \\
\text { cooperating with SME clients for } \\
\text { promoting a circular economy? }\end{array}$ & $\begin{array}{l}\text { Have you cooperated with any of your SME } \\
\text { clients on the topic of CE? }\end{array}$ \\
\hline & If yes, what were the experiences? \\
\hline & In what form was the cooperation? \\
\hline $\begin{array}{l}\text { 3. Which opportunities do the WMFs see to } \\
\text { cooperate more intensely with SMEs in } \\
\text { order to facilitate a circular economy? }\end{array}$ & $\begin{array}{l}\text { What opportunities do you see for cooperating } \\
\text { with your SME clients on promoting a CE? }\end{array}$ \\
\hline & $\begin{array}{l}\text { What practical possibilities are there for } \\
\text { cooperation? }\end{array}$ \\
\hline $\begin{array}{l}\text { 4. Which customers of the WMFs would be } \\
\text { the most open to participate in closer } \\
\text { cooperation? }\end{array}$ & $\begin{array}{l}\text { Which SME clients do you think are willing to } \\
\text { cooperate with you on working towards a CE? }\end{array}$ \\
\hline $\begin{array}{l}\text { 5. What are the current barriers and } \\
\text { enablers for cooperative endeavors with } \\
\text { SME clients? }\end{array}$ & $\begin{array}{l}\text { What obstacles do you experience for working } \\
\text { with SME clients towards a CE? }\end{array}$ \\
\hline & $\begin{array}{l}\text { What do you experience as enablers for } \\
\text { working with SME clients on a CE? }\end{array}$ \\
\hline & $\begin{array}{l}\text { In conclusion, what is the most important } \\
\text { thing that needs to be done to get cooperation } \\
\text { between your company and your SME clients } \\
\text { off the ground? }\end{array}$ \\
\hline
\end{tabular}

